\title{
An Experimental Investigation of Ride Control Algorithms for High-Speed Catamarans Part 2: Mitigation of Wave Impact Loads
}

\author{
Javad AlaviMehr ${ }^{1}$, Jason Lavroff ${ }^{1}$, Michael R. Davis ${ }^{1}$, Damien S. Holloway ${ }^{1}$, Giles A.Thomas ${ }^{2}$ \\ ${ }^{1}$ University of Tasmania \\ ${ }^{2}$ University College London
}

\begin{abstract}
High-speed craft frequently experience large wave impact loads due to their large motions and accelerations. One solution to reduce the severity of motion and impact loadings is the installation of ride control systems. Part 1 of this study investigates the influence of control algorithms on the motions of a $112 \mathrm{~m}$ high-speed catamaran using a $2.5 \mathrm{~m}$ model fitted with a ride control system. The present study extends this to investigate the influence of control algorithms on the loads and internal forces acting on a hydro-elastic segmented catamaran model. As in Part 1, the model active control system consisted of a centre bow T-Foil and two stern tabs. Six motion control feedback algorithms were used to activate the model scale ride control system and surfaces in a closed loop system: local motion, heave and pitch control, each in a linear and nonlinear application. The loads were further determined with a passive ride control system and without control surfaces fitted for direct comparison. The model was segmented into seven parts, connected by flexible links that replicate the first two natural frequencies and mode shapes of the $112 \mathrm{~m}$ INCAT vessel, enabling isolation and measurement of a centrebow force and bending moments at two cross-sections along the demi-hulls. The model was tested in regular head seas at different wave heights and frequencies. From these tests it was found that the pitch control mode was most effective and in 60 mm model scale waves it significantly reduced the peak slam force by $90 \%$ and the average slam induced bending moment by $75 \%$ when compared to a bare hull without ride controls fitted. This clearly demonstrates the effectiveness of a ride control system in reducing wave impact loads acting on high-speed catamaran vessels.
\end{abstract}

\section{Nomenclature}

$a \quad$ Distance between centre of elastic link and centreline of the demi-hull pin joint mount (m)

$b \quad$ Distance between centre of starboard and port elastic links of centre bow transverse beams $(\mathrm{m})$

$c \quad$ Distance between centreline of forward and aft centre bow transverse beams (m)

$C_{L \alpha} \quad$ Control surface lift coefficient derivative $\left(d C_{L} / d \alpha\right)$ (dimensionless) 
$d \quad$ Position of force acting on each centre bow transverse beam measured from the centreline of the port demi-hull pin joint mount (m)

E $\quad$ Elastic modulus $\left(\mathrm{N} / \mathrm{m}^{2}\right)$

F $\quad$ Force acting on either centre bow transverse beam (N)

$F_{1} \quad$ Force acting on forward centre bow transverse beam $(\mathrm{N})$

$F_{2} \quad$ Force acting on aft centre bow transverse beam (N)

$F_{T} \quad$ Total force acting on centre bow (N)

$H \quad$ Model heave at LCG (m, positive up)

I Second moment of area of cross section $\left(\mathrm{m}^{4}\right)$

$L C G \quad$ Longitudinal Centre of Gravity

$M \quad$ Bending moment (N.m)

$M_{l} \quad$ Bending moment acting on port elastic link of each centre bow transverse beam (N.m)

$M_{2} \quad$ Bending moment acting on starboard elastic link of each centre bow transverse beam (N.m)

$P \quad$ Model pitch about LCG (radian, positive bow down)

$S_{S T} \quad$ Stern tab planform area $\left(\mathrm{m}^{2}\right)$

$S_{T F} \quad$ T-Foil planform area $\left(\mathrm{m}^{2}\right)$

$x_{F} \quad$ Position of total force acting on centre bow measured from the centreline of the aft transverse beam (m)

$x_{S T} \quad$ Distance between centre of pressure of the stern tabs and LCG (m)

$x_{T F} \quad$ Distance between centre of pressure of the T-Foil and LCG (m)

$y_{l} \quad$ Distance between strain gauges on an elastic link (m)

$\epsilon \quad$ Differential strain measured on elastic link

$\alpha_{S T} \quad$ Stern tabs angular deflection (radian, positive producing upward lift)

$\alpha_{S T d} \quad$ Control system demand stern tabs angular deflection (radian, positive producing upward lift)

$\alpha_{T F} \quad$ T-Foil angular deflection (radian, positive producing upward lift)

$\alpha_{T F d} \quad$ Control system demand T-Foil angular deflection (radian, positive producing upward lift)

\section{Introduction}

Catamaran vessels operating at high-speed often experience slam events and associated large wave loads when the vessel motion causes an impact between the cross deck structure and the water surface [1]. The Catamaran twin hull configuration with a flat wet-deck section joining the two demi-hulls is effective during operation in smaller waves but is prone to deck diving in larger waves due to low reserve buoyancy in the forward part of the vessel. 
This causes the flat wet-deck to make contact with the water surface, leading to very large impulsive slam loads on the hull structure [2-4] and in severe cases to green water over the bow and substantial structural damage. INCAT Tasmania [5] have developed a unique configuration of high-speed wave-piercing catamarans with a prominent short centre bow located on the vessel centreline between the wave-piercer demi-hulls designed to effectively eliminate deck diving in following seas. The centre bow provides forward buoyancy to the front of the vessel above the calm water line during wave slam impact [6].

As described previously [7] active motion control systems used by INCAT Tasmania [5] for high-speed wave piercing catamarans consist of two active trim tabs located at the stern of the vessel demi-hulls and a retractable TFoil mounted on the centreline at the aft end of the centre bow. Figure 1 of the previous paper [7] shows the location of the T-Foil and the trim tabs on a 112 m INCAT Tasmania high-speed wave-piercing catamaran.

It has been found at full scale that by controlling motions, particularly pitch, bow entry and slamming can be minimized [8]. In these full scale tests the ride control system was operated in a pitch control mode. The bow entry and slam events cause major structural loads that can be significantly reduced through the implementation of motion control [9]. There have been prior studies of structural loads relevant to this type of fast ship and the problem has been investigated both experimentally and numerically. A time domain method was developed by Davis et al. to validate the nonlinear wave loads measured in sea trials of an $86 \mathrm{~m}$ catamaran [10] and it was found that unsteady stress and encountered wave data measured on the catamaran ferry were in close agreement with predicted loads over a wide range of speed. Davidson et al. presented the results of studies into the calculation of global loads on a $112 \mathrm{~m}$ wave-piercing catamaran design [11] where they compared previous wave-piercing catamaran designs with strict attention to weight reduction and building cost by controlling maximum plate thicknesses through a series of design studies on global and local structure. The methodology of global load verification for an INCAT 98 meter class catamaran was investigated by Roberts et al. [12] and research into global load predictions for larger designs was carried out. It was found that based on measured strains and derived bending moments, the global strength of the $98 \mathrm{~m}$ vessel appeared adequate for the rough weather trials [12]. Computational modelling of wet deck slam loads of an INCAT 96 m wave-piercing catamaran with reference to sea trial data was conducted by Davis et al. [13] and it was found that the two dimensional representations of the slam entry load exceeds the largest slam which had so far been observed in sea trials by a factor of about three. Davis et al. proposed that the vertical momentum method be applied in ship motion and loading computations with a correction factor to reduce predicted loads so as to better correlate with observed maximum slam loading 
[13]. Slamming loads on large high-speed wave piercers were also investigated by Amin et al. using a reverse engineering method in conjunction with trials data and finite element analysis [14]. Their results showed that the comparison method with trials is critical and dynamic analysis is required to fully understand and develop a realistic interpretation of slamming loads during trials. The vibratory response of high-speed catamarans to slamming was investigated by Lavroff et al. [15] through hydro-elastic segmented model experiments and a good correlation between experimental measured quantities and theoretical values for both wet and dry experiments was found. This work using a hydro-elastic segmented model experiments was extended by Lavroff et al. to determine the wave slamming loads on high-speed catamarans $[16,17]$, and it was found that slam loads peaked in the same range of encounter frequency as did the peak global dimensionless heave and pitch accelerations . The slam events of high-speed catamarans in irregular waves were characterised through towing tank testing of a hydro-elastic segmented model by Thomas et al. [18] where slams were found to have a large range of magnitudes, with the largest equivalent to 1785 tonnes full scale (approximately $70 \%$ of vessel displacement). However, the majority of events were of relatively low severity. This work was extended by French et al. [19] and a slam occurrence threshold was identified by extrapolating the experimentally measured occurrence rates. Mitigation of slamming of large wave-piercing catamarans by bow design was investigated by Shahraki et al. [20] and it was found that increases of wet deck height reduce impulsive slam loadings but lead to increased motions. Shahraki et al. also found that shorter centre bows reduce slam loadings and also reduce the vessel pitch motions [20].

Although there have been many investigations into catamaran structural loads through numerical computations, model experiment and full-scale sea trials, the influence of ride control systems on structural loads has had only limited research undertaken. The effect of the ride control algorithms on model motions in waves has been previously investigated by the authors [7]. It was concluded that the ride control system can significantly reduce the model motions. Motions were most reduced with a nonlinear pitch control mode, where the maximum pitch Response Amplitude Operator (RAO) was reduced by up to $50 \%$ in $2.69 \mathrm{~m}$ (full scale) waves and the vertical acceleration near the bow by about $40 \%$ at the same model test conditions. In light of the ride control influence in reducing relative motions between the bow and water surface [7], it is clear that there are significant gains that can be achieved through the implementation of a ride control system with regard to reduction of wave impact slamming. This previous study thus establishes a basis for the current investigation which is to evaluate the influence of the ride control system on the structural loads during model tests undertaken in regular waves. 


\section{Hydro-elastic modelling}

The model used for this study is an existing 1/44.8 scale $2.5 \mathrm{~m}$ hydro-elastic segmented catamaran model of the 112 m INCAT Tasmania wave-piercing catamaran which was designed and built at the University of Tasmania. The development of the catamaran model has been previously described by Lavroff et al. [15-17, 21]. The catamaran model was designed to simulate ship hydro-elasticity and to measure motions, wave-induced loads and structural vibratory responses [22]. In order to achieve this, the catamaran model was developed using rigid hull segments with elastic connections [16, 17]. Structural scaling was achieved by tuning of the model whipping mode to a frequency of $13.79 \mathrm{~Hz}$ to represent a full scale modal frequency of $2.06 \mathrm{~Hz}$ [15]. The catamaran model was segmented into seven separate rigid body sections, with each demi-hull segmented into three distinct parts consisting of aft, mid-ship and forward segments. Another section was located between the starboard and port forward demi-hulls, defined as the centre bow. The centre bow was separated from the forward demi-hulls in order to isolate the slamming loads acting on the bow of the model $[16,17]$. There are two longitudinal aluminium backbone beams, two mid-ship transverse beams (which rigidly connect the mid-ship demi-hull segments) and two centre bow transverse beams. The separate segments of the hull were joined using aluminium elastic links. Figure 1(a) shows a schematic diagram of the hydro-elastic segmented catamaran model (from Lavroff [6]).

Elastic links were located in each of the centre bow transverse beams to either side of the main vessel centreline and were fitted with strain gauges to measure the bending strains as shown in Figure 1(b). The elastic links had a rectangular section with strain gauges mounted on top and bottom surfaces. Each pair of strain gauges was installed in a half bridge configuration so that the strain differential indicated the bending moment of the link. Therefore, the bending moment of each elastic link could be easily calculated by acquiring the differential strain on each elastic link and using the link properties, hence

$M=\epsilon \frac{E I}{y_{l}}$,

where $M=$ bending moment, $\epsilon=$ differential strain measured on the elastic link, $y_{l}=$ distance between strain gauges on a link (depth of the flexible link cross section), $E=$ elastic modulus and $I=$ second moment of area of the link cross section about its axis of bending.

With reference to Figure 1(a), the total force acting on the centre bow of the catamaran model was distributed between the two centre bow transverse beams. Figure 2(a) shows a schematic diagram of the force acting on each centre bow transverse beam. Each transverse beam incorporated two elastic links located on the starboard and port 
sides at locations with bending moments $M_{1}$ and $M_{2}$. Both outboard ends of the transverse beam were mounted to pinned connections that were hard mounted on the port and starboard demi-hull backbone beams. Strain gauges were installed on each of the elastic links and were separated by a distance, $b$. The port and starboard strain gauge measurement positions were located at a distance, $a$, from the pinned connections. Strains were measured at each of the elastic links for the evaluation of bending moments, $M_{1}$ and $M_{2}$. The force acting on the forward or aft transverse beam, $F$, and the force position, $d$, were calculated on the basis of the magnitude and position of the measured bending moments neglecting bow inertia loads:

$F=\frac{M_{1}+M_{2}}{a}$

$d=\frac{M_{2}(2 a+b)}{M_{1}+M_{2}}$

In head sea tests the loading would be symmetric and so $d=\frac{2 a+b}{2}$ should apply, subject to accuracy of the measurement system. Figure 2(b) shows a schematic diagram of the transverse beams for the evaluation of the total force acting on the centre bow. The forward and aft transverse beams were pinned to the port and starboard demi-hull backbone beams and separated by width $c$. The total force acting on the centre bow, $F_{T}$, was the summation of the forces acting on the forward transverse beam, $F_{1}$, and the aft transverse beam, $F_{2}(4)$. The evaluation of the longitudinal position of the total force, $x_{F}$, was thus calculated based on these known parameters (5),

$F_{T}=F_{1}+F_{2}$

$x_{F}=\frac{F_{1}}{F_{1}+F_{2}} c$.

Static loading tests on the model showed that the method used as illustrated in Figure 2 correctly identified the fore and aft location of the load on the bow using Equations 4 and 5 and that the pin mountings on the demi-hulls did not therefore transmit a significant torsional moment to the transverse bow support beams.

\section{Ride control algorithms}

The model was tested with different ride control conditions including no RCS, passive RCS and active RCS (heave control, local motion control and pitch control). Linear and non-linear gains were applied for each control mode. In the linear modes the feedback gains were selected so that the control motions remained within their 
maximum range of physical movement whilst in the non-linear modes the gains were set at large values and the control surfaces then moved rapidly between extreme positions giving maximum control forces at all times. The control algorithms are described in detail in the previous paper [7] and are briefly outlined here. It should be noted that the control actions are subject to demand inputs derived from the model heave and pitch motion signals on the basis that the RCS acts as a damping system. The broad philosophy behind this approach is that the RCS has limited maximum forces and so is best deployed as a motion damping system rather than a direct motion feedback control. However, as has been found in the previous testing $[7,23,24]$ the electric servo system driving the physical control surfaces from the demand signals does have significant phase shift and so the actual control actions effectively deliver a combination of damping and stiffness control in each mode of operation [7]. This has been found to be particularly beneficial with pitch control at low frequency where the control system has sufficient capacity to re-trim the model even in steady state conditions. However the control system does not have significant capacity to control sinkage and so the phase lag in the actual model system did not benefit the heave control mode to anything like the same extent as the pitch control mode [7].

As previously explained [7], the demanded control deflections for the pitch control mode can be formulated as a pitch damping demand with

$\alpha_{T F d}=e \dot{P}$

$\alpha_{S T d}=k \dot{P}$,

where $\alpha_{T F d}$ and $\alpha_{S T d}$ are the demanded angle of attack deflections of the T-Foil and stern tabs. As shown in detail in Part 1 of this paper [7] , the actual deflections are somewhat phase lagged from these demands.

In pitch control mode the gains $k$ and $e$ must have a defined ratio to ensure that zero net heave force is generated by the controls. The parameter $e$ for linear feedback deflection of the T-Foil is

$e=-\frac{\left(\alpha_{T F d}\right)_{\max }}{\dot{P}_{\max }}$.

The value of the gain $e$ can then be determined from the known maximum T-Foil deflection and an estimated maximum pitch rate [7]. The maximum pitch rate can be estimated from the wave encounter angular frequency, maximum pitch and the Froude number.

The demanded excitation forces applied to the hull by the ride control surfaces in heave and pitch are determined by the demand signals input to the control surfaces and their consequent change of angle of attack $[7,23,24]$. 
The control parameter $k$ for the linear deflection of stern tabs [7] is then given by

$k=-e \frac{S_{T F}\left(C_{L \alpha}\right)_{T F}}{2 S_{S T}\left(C_{L \alpha}\right)_{S T}}$

The control surfaces lift coefficient derivatives $\left(C_{L \alpha}\right)$ were determined from previous studies on the T-Foil [23] and stern tabs [25]. As previously explained [7] the T-Foil reaches the limit of its range before the stern tabs and therefore the parameter $e$ is determined by Equation 8 in terms of the maximum T-Foil deflection and the parameter $k$ is determined by Equation 9 in terms of $e$. Thus, the stern tabs operate at less than their full range of action.

For the heave control mode the demanded control deflections are

$\alpha_{T F d}=b \dot{H}$

$\alpha_{S T d}=h \dot{H}$.

The parameter $b$ then follows from the maximum deflection of the T-Foil and the maximum heave velocity,

$b=-\frac{\left(\alpha_{T F d}\right)_{\max }}{\dot{H}_{\max }}$

For the heave control mode the total pitch moment about the LCG induced by the control surfaces must be zero, thus

$h=b \frac{x_{T F} S_{T F}\left(C_{L \alpha}\right)_{T F}}{x_{S T} S_{S T}\left(C_{L \alpha}\right)_{S T}}$,

where $x_{T F}$ and $x_{S T}$ are the distances between the LCG and the centre of pressure of the T-Foil and the stern tabs respectively. The T-Foil reaches the limit of its range before the stern tabs when the actions are balanced to give zero pitch and so parameter $b$ is determined by Equation 12 and parameter $h$ is determined by Equation 13 .

In local control mode the control surfaces act independently and have input demands to oppose the local vertical velocities. The principle here is simply that this action extracts maximum energy from any dynamic motion. As explained previously [7], the vertical velocities of the model at the longitudinal location of each control surface are $\dot{H}-x_{T F} \dot{P}$ and $\dot{H}+x_{S T} \dot{P}$ for the T-Foil and stern tab respectively. Thus in the local control mode we require control surface demands $\alpha_{T F d}=b\left(\dot{H}-x_{T F} \dot{P}\right)$ and $\alpha_{S T d}=h\left(\dot{H}+x_{S T} \dot{P}\right)$, where

$b=-\frac{\left(\alpha_{T F d}\right)_{\max }}{\dot{H}_{\max }}$

$h=-\frac{\left(\alpha_{S T d}\right)_{\max }}{\dot{H}_{\max }}$.

Thus

$e=-b \times x_{T F}$ 
$k=h \times x_{S T}$.

It is recognised [7] that the control surfaces are not large enough to cancel motions altogether in large waves. Therefore a nonlinear version of each algorithm is introduced [7]. In each nonlinear control mode the control surfaces are moved to their maximum angular offsets as quickly as the mechanisms will allow [24], thus giving demand control surface deflections

$\alpha_{T F d}= \pm\left(b \dot{H}_{\max }+e \dot{P}_{\max }\right)$

$\alpha_{S T d}= \pm\left(h \dot{H}_{\max }+k \dot{P}_{\max }\right)$

The constants $b, e, h$ and $k$ are determined [7] in the same way as for each linear control action so that the maximum lift force or moment opposes the relevant velocity term (heave, pitch or local). Thus the maximum control forces at the extreme point of motion velocity will remain unaltered but the forces or moments opposing the velocities will remain at the maximum for a longer duration within the motion half cycles [7].

\section{Tank testing to identify slam loadings}

Model testing in the towing tank for the present work was conducted as has been described previously [7]. The model has a displacement of $28.3 \mathrm{~kg}$, equivalent to a full scale displacement of 2545 tonnes, and an overall length of $2.5 \mathrm{~m}$ equivalent to the full scale length of $112 \mathrm{~m}$. Figure 8 of the previous paper [7] shows the model attached to the moving carriage. Data for model motions was derived from Linear Variable Differential Transformers (LVDTs) mounted on the forward and aft tow posts. These motion signals and elastic link strains were logged using two National Instruments systems which also included digital to analogue converters to generate demand signals for the three control surface servo-motors [7]. The two data recording systems were synchronised using a common reference signal. The motion data was sampled at $50 \mathrm{~Hz}$ while the strain gauge data was sampled at 1613 Hz. LabVIEW programs were used to record data and to generate the demand signals for the control surfaces from the motion signals.

The model was tested in regular waves at a model speed of $2.89 \mathrm{~m} / \mathrm{s}$ (equivalent to a full scale speed of $37 \mathrm{knots}$ ) at two wave heights $(60 \mathrm{~mm}$ and $90 \mathrm{~mm}$, equivalent to full scale wave heights of $2.69 \mathrm{~m}$ and $4.03 \mathrm{~m})$. Wave frequencies ranging from $0.350 \mathrm{~Hz}$ to $0.900 \mathrm{~Hz}$ were generated by the towing tank wave maker for each test condition. Table 2 of the previous paper [7] summarises the model test conditions. 
The influence of the ride control system on the model structural loads was investigated by analysing the data obtained from the strain gauges installed on the model centre bow and demi-hull links. Raw strain gauge data obtained from the towing tank tests were analysed and the forces on the centre bow and the slam induced bending moments in the demi-hulls were recorded as time records. These records were used to determine extreme loadings. The centre bow loads are presented in parts: firstly, a centre bow entry force, which develops relatively slowly as the bow enters the water prior to a slam occurring, at which point water reaches the top of the arched cross section between demi-hulls; secondly, a rapidly rising slam force occurring when the cross section fills and water impacts the arch top; and thirdly, a total force comprising the sum of these two components. The position of the centre bow slam force from the transom is determined as a function of wave height and wave encounter frequency for different ride control algorithms. The slam induced bending moments are shown for the forward and aft segment of demi-hull. Extremes of all the above mentioned results are presented at two points in the whole slam event representing extreme sagging and hogging loads.

The strain gauge data and the motion data were acquired simultaneously. Figures 3(a) and (b) show sample time records at model speed of $2.89 \mathrm{~m} / \mathrm{s}(\mathrm{Fr}=0.608)$, wave height of $90 \mathrm{~mm}$ and dimensionless wave encounter frequency $\omega_{e}^{*}=4.581$ for the passive RCS and pitch control mode respectively. It should be noted that the wave profile at the LCG, centre bow total force and the heave motion are all positive upwards, the pitch motion is positive bow down and the control surfaces deflection are positive counter-clockwise viewed from the starboard side, producing upward lift. As can be seen from Figure 3, the pitch control mode reduced the centre bow total force, clearly demonstrating the effect of motion control on the loads response of the model in this mode.

The strain gauge data obtained during all towing tank tests undertaken on the catamaran model were analysed to identify the maximum centre bow entry force, the maximum total force and the slam force acting on the centre bow, and the maximum slam induced bending moments acting on the demi-hull. The onset of slamming and the relevant procedure has been previously discussed by Lavroff et al. $[16,17]$ where a minimum peak slam load threshold was developed to identify the onset of the wet-deck slam event. However, Lavroff et al. [16, 17] presented only the total centre bow force whereas here we have broken this down into the bow entry and slam components. The strains measured on the elastic links in the transverse bow mounting beams were converted to bending moments and thus used to calculate the force acting on the centre bow and its longitudinal location. The raw strain data acquired from the strain gauges installed on the demi-hull elastic links were used to directly calculate the bending moments in the catamaran model demi-hulls. 
In order to evaluate the extremes of the signals, a range of the time record was analysed, starting when regular periodic motions had been reached and including at least five cycles. An average of the extremes of all these cycles is then presented. This analysis was carried out by finding the peak and trough of each cycle.

The accuracy of the results was established by uncertainty analysis performed based on the standard deviation of the observations. For each run the time record included from 5 to 19 useable cycles after transients had dissipated and before either the run terminated or reflections or other forms of contamination became significant. The variation between the cycles in each run was analysed in order to quantify the accuracy of the results. The standard deviation analysis of the results shows an average of $\pm 3.0 \%$ variation for the centre bow force and $\pm 3.5 \%$ variation for the slam induced bending moment. Figures 4(a) and (b) illustrate these uncertainty of results for some typical cases at a wave height of $60 \mathrm{~mm}$. They show the error bars on the centre bow total sagging force and demi-hull slam induced sagging bending moment for three of the ride control conditions: without RCS, passive RCS and pitch control mode. Drift errors in the instrumentation were compensated by means of daily calibration of the measurement system, these effects being less than the deviations in the sampled data analysis. These curves illustrate the substantial changes brought about by the most successful ride control algorithm. As can be seen from Figure 4 the uncertainty in the results within each case is insignificant compared to the overall effect of the ride control system. Thus the experimental uncertainty has no impact on the key conclusions of this research, and in view of the quantity of data subsequent results will be presented without error bars.

\section{Effect of ride control system on slam loading}

\subsection{Centre bow forces}

The centre bow forces, as previously explained, are divided into three parts: the centre bow entry force, the total centre bow force and the slam force. The slam force is actually the difference between the total force and the centre bow entry force. Figure 5 shows a sample time record of centre bow force demonstrating the centre bow entry force as well as the total sagging and hogging force acting on the bow. It is to be noted that the peak located between the total hogging force and total sagging force in each cycle was considered as the centre bow entry force for that particular cycle.

Figures 6(a) and (b) show the centre bow entry force at wave heights of $60 \mathrm{~mm}$ and $90 \mathrm{~mm}$ respectively. As can be seen from Figure 6(a), although the passive RCS can reduce the peak centre bow entry forces, this force is more strongly mitigated when the ride control system is running in pitch control mode. Both local and heave control algorithms show a better reduction of the centre bow entry forces at the lower dimensionless wave encounter 
frequencies up to $\omega_{e}^{*}=4.5$. The effect of non-linearity of the ride control system on the centre bow entry forces is not significant. Figure 6(b) shows that both passive and active ride control systems do not have a strong influence on the centre bow entry force at the wave height of $90 \mathrm{~mm}$, however the pitch control algorithm can slightly reduce the centre bow entry force.

As for the centre bow entry force, in order to evaluate the peak total sagging force acting on the centre bow at least five cycles at steady state were analysed and an average of the peaks was calculated. Simultaneously an average of the troughs was evaluated to specify the total hogging force acting on the centre bow of the catamaran model. The centre bow total forces were evaluated as a function of wave height and wave frequency for different ride control algorithms. In addition to the different ride control conditions, the results of the model test without RCS studied by Lavroff [16] are presented in order to compare with the results of the model test with RCS. Figures 7(a) and (b) show the centre bow total sagging force at wave heights of $60 \mathrm{~mm}$ and $90 \mathrm{~mm}$ respectively.

It is observed in Figure 7(a) that the maximum total sagging force measured on the bow at a model speed of 2.89 $\mathrm{m} / \mathrm{s}$ and wave height of $60 \mathrm{~mm}$ was $169 \mathrm{~N}$ and occurred at $\omega_{e}^{*}=5.235$ while the model was running without a ride control system. These results demonstrate that the ride control system can substantially reduce the centre bow total sagging force and is most effective in the pitch control mode, where the sagging slam force was significantly reduced by about $85 \%$. The local and heave control algorithms show a similar trend to the passive RCS, however compared to the passive RCS results they increased the total sagging force at the dimensionless wave encounter frequencies higher than 4.5. This may be due to increased RCS phase lag at high frequencies [7].

As can be seen from Figure 7(b), although the pitch control algorithm reduced the total sagging force measured on the bow at a wave height of $90 \mathrm{~mm}$, the ride control system at a wave height of $90 \mathrm{~mm}$ does not show as strong as effect on the centre bow total sagging force at wave height of $60 \mathrm{~mm}$. This is simply due to the limited capacity of the controls, which become relatively less effective in larger seas.

Figures 8(a) and (b) show the centre bow total hogging force at a wave height of $60 \mathrm{~mm}$ and $90 \mathrm{~mm}$ respectively. As can be seen from Figure 8(a), the maximum total hogging force measured on the bow at a model speed of 2.89 $\mathrm{m} / \mathrm{s}$ and wave height of $60 \mathrm{~mm}$ was $132 \mathrm{~N}$ and occurred at $\omega_{e}^{*}=5.235$ when the model was without RCS. The passive ride control system can reduce the maximum peak total hogging force by about $25 \%$ from $132 \mathrm{~N}$ to $97 \mathrm{~N}$. The heave and local control modes reduced the total hogging force and as expected from previous results, the nonlinear pitch control mode had the most significant influence on the reduction of the total hogging force, where it reduced the centre bow total hogging force by around $70 \%$. It is observed in Figure $8(\mathrm{~b})$ that the ride control system has a more limited effect on the peak total hogging force at the wave height of $90 \mathrm{~mm}$. 
Finally, Figures 9(a) and (b) show the centre bow sagging slam force at a wave height of $60 \mathrm{~mm}$ and $90 \mathrm{~mm}$ respectively. These results clearly demonstrate the effect of the ride control system in mitigating the centre bow peak slam force, which is most evident in the pitch control mode where it reduced the peak slam force by about $90 \%$ in $60 \mathrm{~mm}$ waves. The effect of the RCS in $90 \mathrm{~mm}$ waves is again less profound when compared to the $60 \mathrm{~mm}$ case and follows a similar trend to the previous force results for the $90 \mathrm{~mm}$ test case.

The force positions for both sagging and hogging were calculated from the strains measured on the centre bow elastic links. Figures 10(a) and (b) show the positions of the total sagging force measured from the transom of the catamaran model as a function of wave encounter frequency at wave heights of $60 \mathrm{~mm}$ and 90 mm respectively and Figures 11(a) and (b) similarly show the positions of the total hogging force. As can be seen from Figure 10 and 11 , most of the total forces acting on the centre bow of the catamaran model occurred between $1800 \mathrm{~mm}$ to $2000 \mathrm{~mm}$ from the transom of the model for all the test cases considered with and without the RCS. This is close to the centre bow truncation at a distance of $1900 \mathrm{~mm}$ from the transom, a result consistent with the findings of Lavroff et al [16].

\subsection{Demi-hull slam induced bending moments}

The evaluation of the slam induced bending moments followed the same procedure as developed for calculating the centre bow forces. The peaks and troughs of the bending moment for at least five cycles at steady state of each individual model test run were selected and averaged to produce the hogging and sagging bending moment for the given test condition. The slam induced bending moments are presented for both forward and aft segment links of the segmented catamaran model, as previously shown in Figure 1(a).

Figures 12(a) and (b) show the sagging slam induced bending moments measured on the forward segment links of the catamaran model as a function of wave encounter frequency at wave heights of $60 \mathrm{~mm}$ and $90 \mathrm{~mm}$ respectively, while Figures 13(a) and (b) show the corresponding hogging moments. Similarly Figures 14 and 15 show sagging and hogging moments respectively measured on the aft segment links at these two wave heights. The bending moment shown in each of these figures is the summation of the bending moments measured at the respective demi-hull port and starboard elastic links.

As can be seen from Figure 12(a), both linear and non-linear pitch control modes significantly reduced the sagging slam induced forward segment link bending moments by about $80 \%$. The other ride control algorithms were still effective, giving about $50 \%$ reduction of the sagging slam induced forward link bending moments. As expected, and evident in Figure 12(b), the ride control system at wave height of $90 \mathrm{~mm}$ was not as effective as it was at 
wave height of $60 \mathrm{~mm}$, as was the case for the slam impact loads. However, the pitch control mode does show a reduction of about $30 \%$ in the sagging slam induced forward link bending moments at the larger wave height of 90 $\mathrm{mm}$.

Figure 13(a) shows about 75\% mitigation of the hogging slam induced forward segment link bending moments by the pitch control algorithm at a wave height of $60 \mathrm{~mm}$. However, Figure 13(b) demonstrates that there is very little effect of the ride control system on the hogging slam induced forward link bending moments at a wave height of $90 \mathrm{~mm}$.

Figure $14(\mathrm{a})$ also shows a reduction of about $75 \%$ in the sagging slam induced bending moments measured on the aft segment links by both linear and nonlinear control modes at a wave height of $60 \mathrm{~mm}$, and as can be seen from Figure 15(a), the linear and nonlinear pitch control algorithms reduced the hogging slam induced bending moments measured on the aft segment links by around $75 \%$ at a wave height of $60 \mathrm{~mm}$.

Comparing the results of the slam induced bending moments presented in Figures 12 to 15 with the results of the centre bow forces presented in Figures 6 to 9, the direct influence of the centre bow forces on the model bending is immediately apparent. It is observed that increases in the wave height from $60 \mathrm{~mm}$ to $90 \mathrm{~mm}$ gave rise to increases in the centre bow forces as well as slam induced bending moments. The demi-hull slam induced sagging response was on average greater than the hogging response. The slam induced demi-hull bending moments were broadly found to reduce with reductions of the centre bow slam forces.

\section{Conclusions}

The influence of the ride control system on the structural loads and internal forces of a $112 \mathrm{~m}$ INCAT high-speed catamaran was investigated by towing tank testing of a 2.5 m hydro-elastic segmented catamaran model fitted with a model active ride control system consisting of a centre bow T-Foil and two stern tabs. Six motion control feedback algorithms were developed to activate the model scale ride control systems in a closed loop system: local motion, heave and pitch control, each in a linear and nonlinear application. The model structural loads responses were further compared with those using a passive control system and without control surfaces fitted. The hydroelastic segmented catamaran model was tested in regular head seas at different wave heights and frequencies and the centre bow slam loads and the slam induced bending moments in the demi-hulls were analysed using the raw strain gauge data obtained from the towing tank tests. 
The centre bow load results show that the ride control system can reduce the centre bow slam force most strongly in the pitch control mode where it reduced the peak slam force by about $90 \%$ in $60 \mathrm{~mm}$ waves at model scale compared to the model with no ride control system.

The centre bow slam forces had a direct association with the model demi-hull bending moments. Increases in the wave height gave rise to increases in the slam induced loads and bending moments. The demi-hull slam induced sagging bending moment was on average greater than the hogging bending moment. The peak slam induced demihull bending moments occurred simultaneously with the peak centre bow slam loads. The pitch control mode most strongly reduced the slam induced hull bending moments by around $75 \%$ in $60 \mathrm{~mm}$ waves at model scale compared to the model with no control system.

In conclusion, the slam loads observed in this study demonstrate the potential for significant benefit in structural load reduction being obtained by using improved ride control algorithms. There is thus good potential for mitigating the dynamic structural loads experienced by vessels, an important consideration for future design in particular for vessels operating in severe sea conditions.

\section{Acknowledgements}

This project is supported by Australian Research Council Linkage grant No. LP-0883540. The support of INCAT Tasmania Pty. Ltd., Revolution Design Pty. Ltd., the University of Tasmania, and the Australian Maritime College is gratefully acknowledged.

\section{References}

[1] G. Thomas, M. Davis, D. Holloway, T. Roberts, S. Matsubara, J. Lavroff, W. Amin, K. Chamberlin, and T. Dove, "Characterisation of slam events of a high-speed catamaran in irregular waves," in FAST: International Conference on Fast Sea Transportation, Athens, Greece, 2009, pp. 177-188.

[2] J. Kvalsvold and O. Faltinsen, "Slamming loads on wetdecks of multihull vessels," in Proc. Int. Conf. Hydroelasticity in Marine Technology, Trondheim, Norway, 1994.

[3] O. Okland, T. Moan, and J. Aarsnes, "Structural response in large twin hull vessels exposed to severe wet deck slamming," in Proc 7th Int Symp on Practical Design of Ships and Mobile Units (PRADS 98), Hague, Netherlands, 1998.

[4] E. M. Haugen and O. Faltinsen, "Theoretical studies of wetdeck slamming and comparisons with full scale measurements," in FAST. Proceedings of the 5th International Conference on Fast Sea Transportation, Seattle, USA, 1999.

[5] http://www.incat.com.au/\#. (2017). 
[6] J. Lavroff, "The slamming and whipping vibratory response of a hydroelastic segmented catamaran model," PhD Thesis, University of Tasmania, 2009.

[7] J. AlaviMehr, J. Lavroff, M. R. Davis, D. Holloway, and G. Thomas, "An Experimental Investigation of Ride Control Algorithms for High-Speed Catamarans Part 1: Reduction of ship motions," Journal of Ship Research, In Press, 2017.

[8] G. Jacobi, G. Thomas, M. Davis, D. Holloway, G. Davidson, and T. Roberts, "Full-scale motions of a large high-speed catamaran: The influence of wave environment, speed and ride control system," International Journal of Maritime Engineering, vol. 154, pp. A143-A155, 2012.

[9] G. Jacobi, G. Thomas, M. R. Davis, and G. Davidson, "An insight into the slamming behaviour of large high-speed catamarans through full-scale measurements," Journal of Marine Science and Technology, vol. 19, pp. 15-32, Mar 2014.

[10] M. Davis, D. Holloway, and N. Watson, "Validation of nonlinear wave loads predicted by time domain method in sea trials of an $86 \mathrm{~m}$ catamaran," in FAST: International Conference on Fast Sea Transportation, St-Petersburg, Russia, 2005, pp. 1-8.

[11] G. Davidson, T. Roberts, and G. Thomas, "Global and slam loads for a large wavepiercing catamaran design," Australian Journal of Mechanical Engineering, vol. 3, pp. 155-164, 2006.

[12] T. Roberts, G. Davidson, M. Davis, G. Thomas, and T. Brady, "Global loads derivation of large high speed vessels," in Pacific 2006 international maritime conference, Sydney, Australia, 2006, p. 535.

[13] M. R. Davis, J. R. Whelan, and G. A. Thomas, "Computational modeling of wet deck slam loads with reference to sea trials," in Proceedings of the 9th International Conference on Fast Sea Transportation, Shanghai, China, 2007, pp. 616-624.

[14] W. Amin, M. Davis, G. Thomas, and D. Holloway, "Slamming quasi-static analysis of an incat 98-m high-speed wave piercing catamaran," in Proceedings of the international conference for innovation in high speed marine vehicles, Fremantle, Australia, 2009.

[15] J. Lavroff, M. R. Davis, D. S. Holloway, and G. Thomas, "The vibratory response of high-speed catamarans to slamming investigated by hydroelastic segmented model experiments," International Journal of Maritime Engineering, vol. 151, pp. 1-11, Oct-Dec 2009.

[16] J. Lavroff, M. R. Davis, D. S. Holloway, and G. Thomas, "Determination of wave slamming loads on high-speed catamarans by hydroelastic segmented model experiments," International Journal of Maritime Engineering, vol. 153, pp. A185-A197, Jul-Sep 2011.

[17] J. Lavroff, M. R. Davis, D. S. Holloway, and G. Thomas, "Wave slamming loads on wave-piercer catamarans operating at high-speed determined by hydro-elastic segmented model experiments," Marine Structures, vol. 33, pp. 120-142, Oct 2013.

[18] G. Thomas, S. Winkler, M. Davis, D. Holloway, S. Matsubara, J. Lavroff, and B. French, "Slam events of high-speed catamarans in irregular waves," Journal of Marine Science and Technology, vol. 16, pp. 821, Mar 2011.

[19] B. J. French, G. A. Thomas, and M. S. Davis, "Slam occurrences and loads of a high-speed wave piercer catamaran in irregular seas," Proceedings of the Institution of Mechanical Engineers, Part M: Journal of Engineering for the Maritime Environment, vol. 229(1), pp. 45-57, 2013.

[20] J. R. Shahraki, M. R. Davis, B. Shabani, J. AlaviMehr, G. A. Thomas, J. Lavroff, and W. A. Amin, "Mitigation of Slamming of Large Wave-Piercing Catamarans," in The 30th Symposium on Naval Hydrodynamics, Hobart, Australia, 2016, pp. 1-13.

[21] J. Lavroff and M. R. Davis, "Slamming kinematics, impulse and energy transfer for wave-piercing catamarans," Journal of Ship Research, vol. 59, pp. 145-161, Sep 2015.

[22] S. Matsubara, G. Thomas, M. R. Davis, D. S. Holloway, and T. Roberts, "Influence of centrebow on motions and loads of high-speed catamarans," in Proceedings of the 11th International Conference on Fast Sea Transportation, Hawaii, USA, 2011, pp. 661-668.

[23] J. AlaviMehr, M. R. Davis, and J. Lavroff, "Low Reynolds Number Performance of a Model Scale TFoil," Royal Institution of Naval Architects. Transactions. Part A3. International Journal of Maritime Engineering, vol. 157, pp. A175-A187, 2015.

[24] J. AlaviMehr, M. R. Davis, J. Lavroff, D. Holloway, and G. Thomas, "Response of a high-speed wavepiercing catamaran to an active ride control system," Royal Institution of Naval Architects. Transactions. Part A4. International Journal of Maritime Engineering, vol. 158, pp. A325-A336, 2016.

[25] J. Bell, T. Arnold, J. Lavroff, and M. Davis, "Measured loading response of model motion control stern tabs," Royal Institution of Naval Architects. Transactions. Part A. International Journal of Maritime Engineering, vol. 155, pp. A1-A7, 2013. 


\section{Figures}

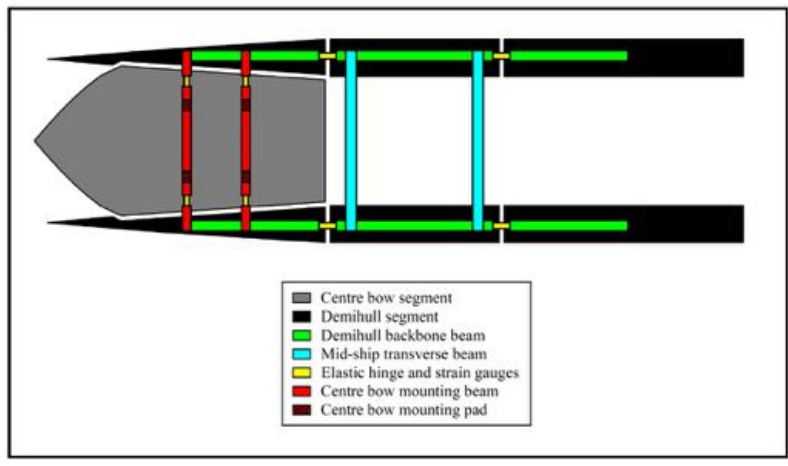

(a)

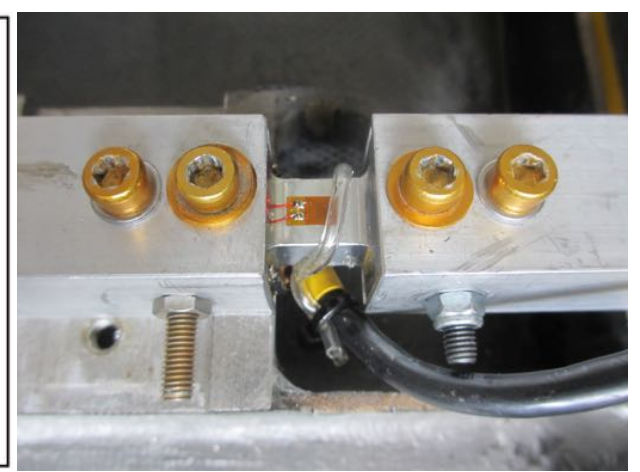

(b)

Figure 1: (a) Schematic diagram of hydro-elastic segmented catamaran model (from Lavroff [6]). (b) Elastic link with strain gauges located on top (visible) and bottom (hidden) surfaces to measure wave induced strains.

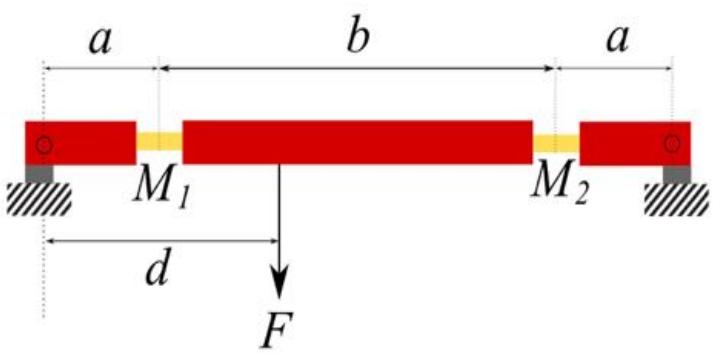

(a)

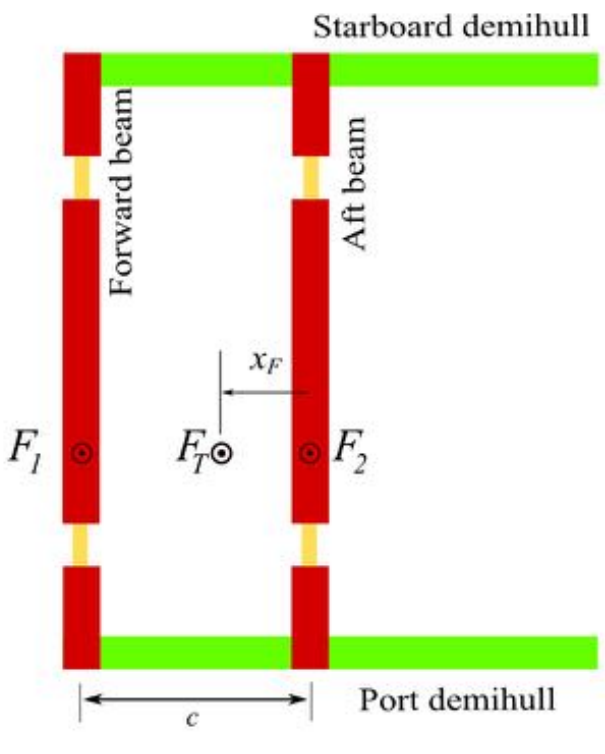

(b)

Figure 2: (a) Schematic diagram of the centre bow transverse beam showing the force acting on each beam. (b) Schematic diagram of the centre bow transverse beams for the evaluation of the total force acting on the centre bow and its location. 


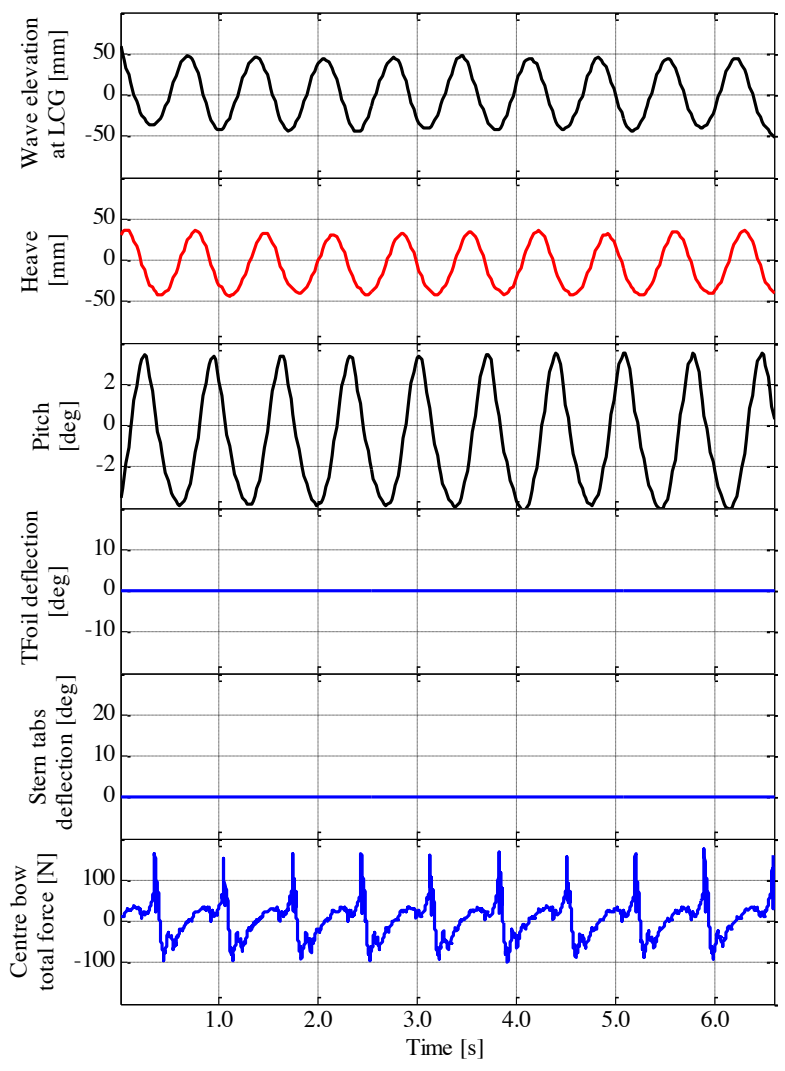

(a) Passive RCS mode

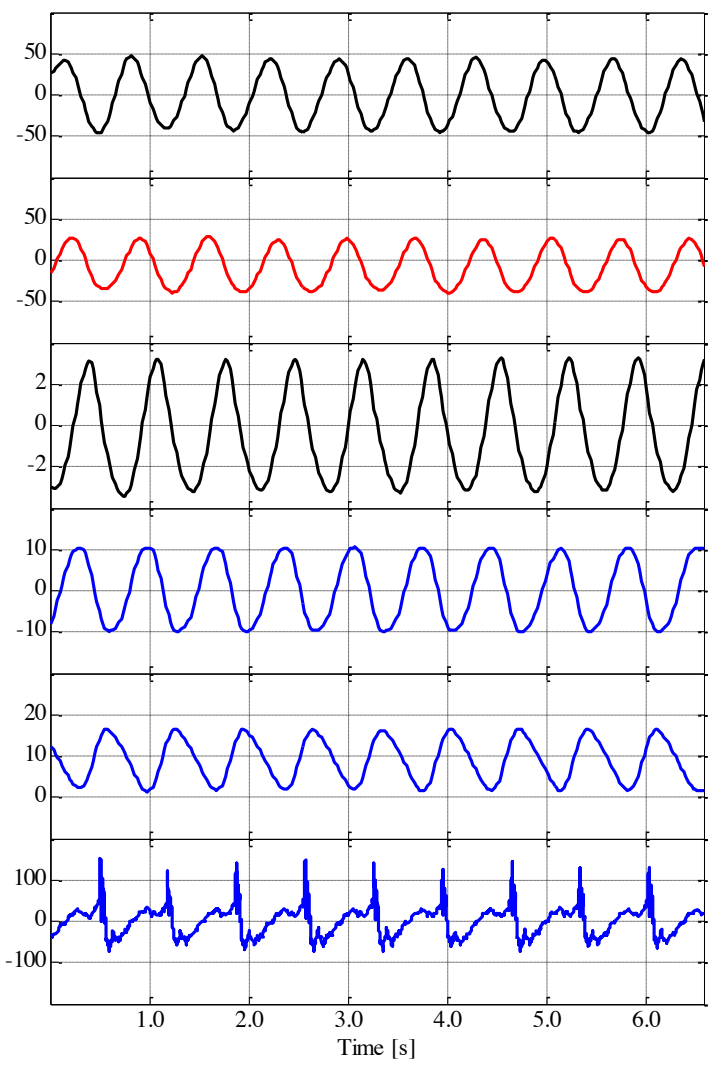

(b) Pitch control mode

Figure 3: Typical time records at a model test speed of $2.89 \mathrm{~m} / \mathrm{s}(\mathrm{Fr}=0.608)$, wave height of $90 \mathrm{~mm}$ and dimensionless wave encounter frequency $\omega_{e}^{*}=4.581$. (a) Passive RCS mode. (b) Pitch control mode.

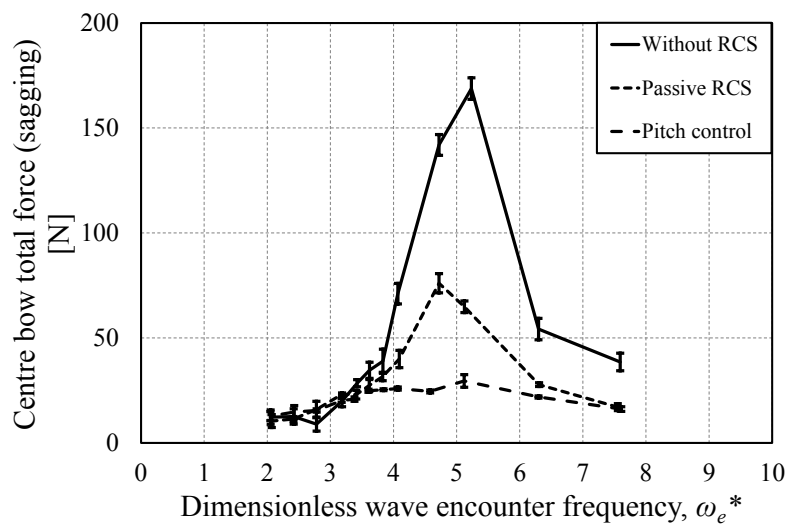

(a)

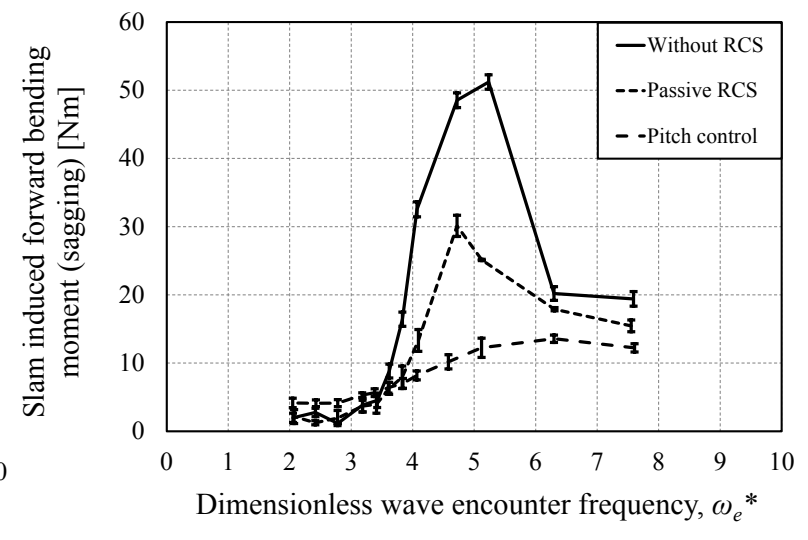

(b)

Figure 4: Error bars for loading data at a model test speed of $2.89 \mathrm{~m} / \mathrm{s}(\mathrm{Fr}=0.608)$ and wave height of $60 \mathrm{~mm}$. (a) Centre bow total sagging force. (b) Demi-hull slam induced sagging bending moment at the forward segment position. 


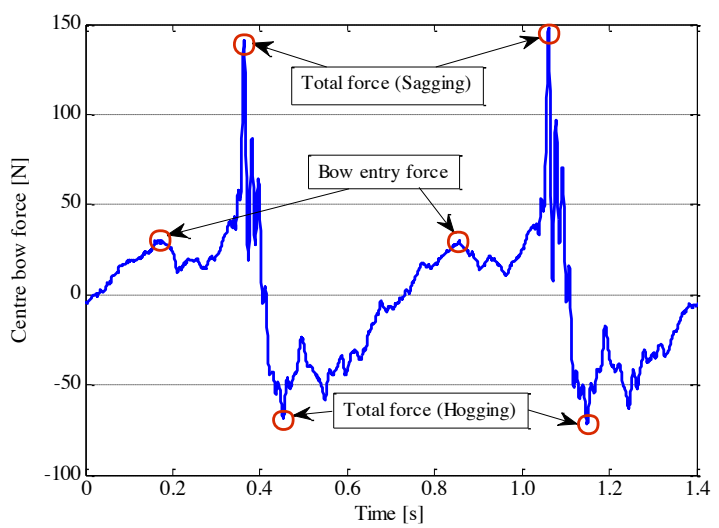

Figure 5: Designation of centre bow entry and total centre bow force using data obtained at model speed of 2.89 $\mathrm{m} / \mathrm{s}(\mathrm{Fr}=0.608)$, wave height of $90 \mathrm{~mm}, \omega_{e}^{*}$ of 4.581 and pitch control mode.

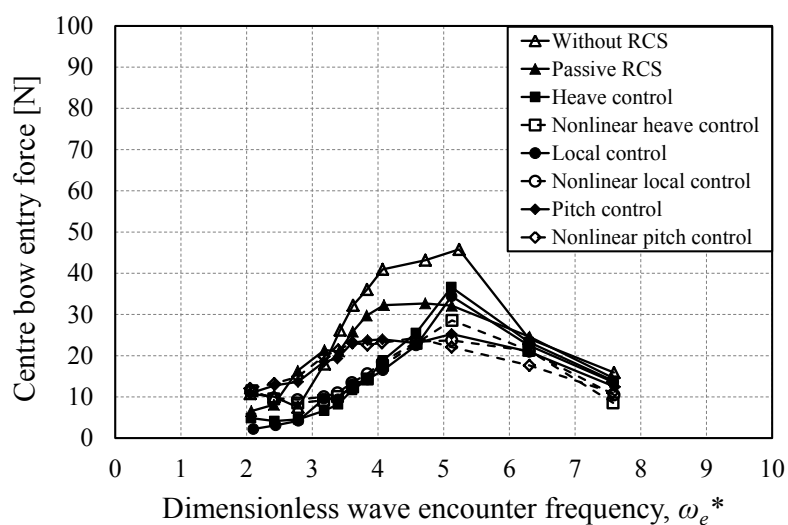

(a)

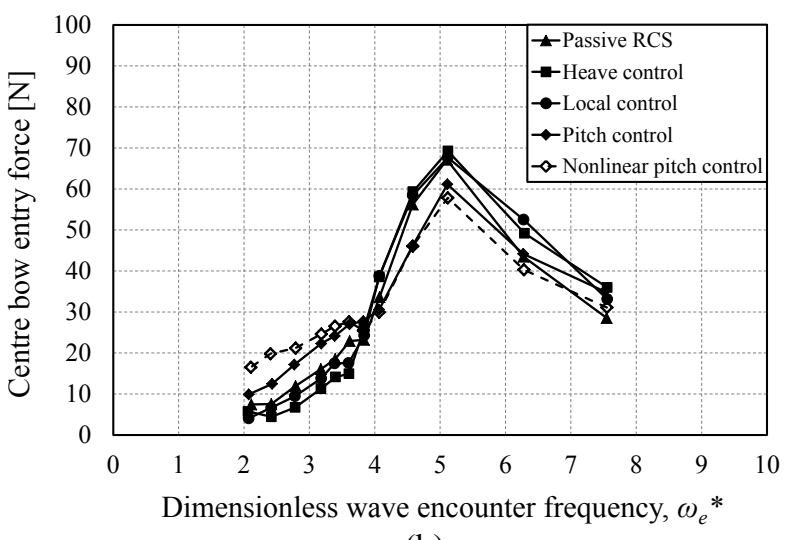

(b)

Figure 6: Centre bow entry force at model speed of $2.89 \mathrm{~m} / \mathrm{s}(\mathrm{Fr}=0.608)$. (a) Wave height of $60 \mathrm{~mm}$. (b) Wave height of $90 \mathrm{~mm}$.

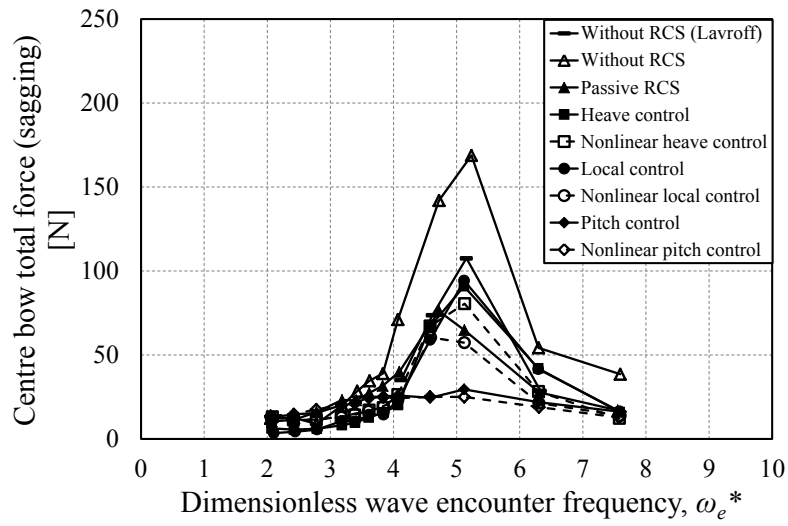

(a)

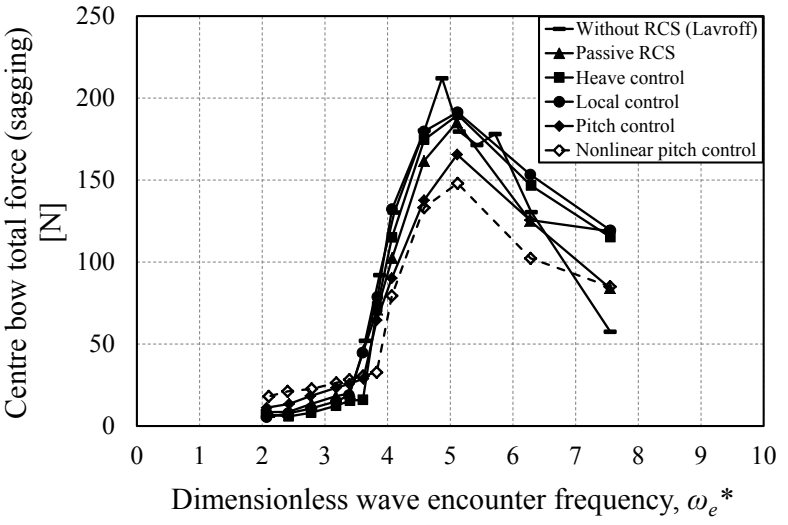

(b)

Figure 7: Centre bow total sagging force at model speed of $2.89 \mathrm{~m} / \mathrm{s}(\mathrm{Fr}=0.608)$. (a) Wave height of $60 \mathrm{~mm}$. (b) Wave height of $90 \mathrm{~mm}$. 


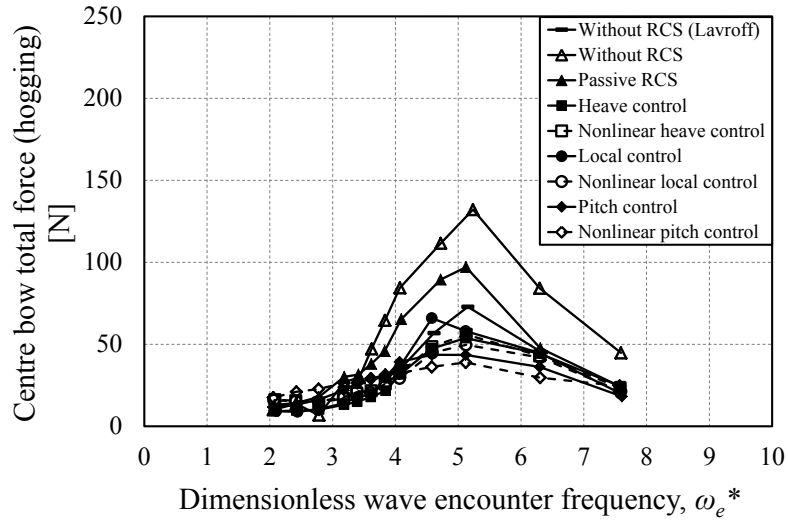

(a)

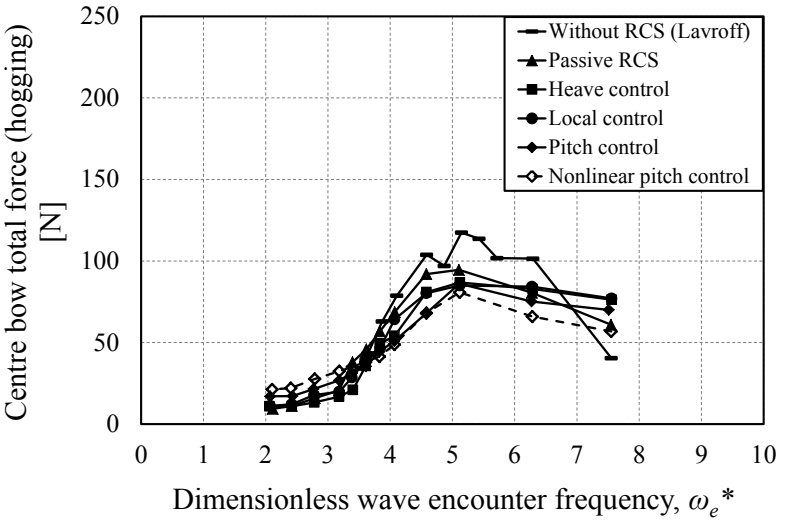

(b)

Figure 8: Centre bow total hogging force at model speed of $2.89 \mathrm{~m} / \mathrm{s}(\mathrm{Fr}=0.608)$. (a) Wave height of $60 \mathrm{~mm}$. (b) Wave height of $90 \mathrm{~mm}$

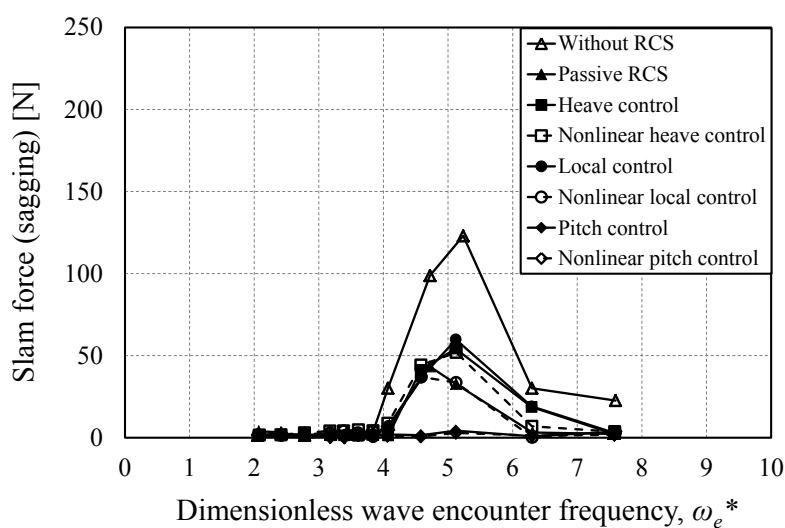

(a)

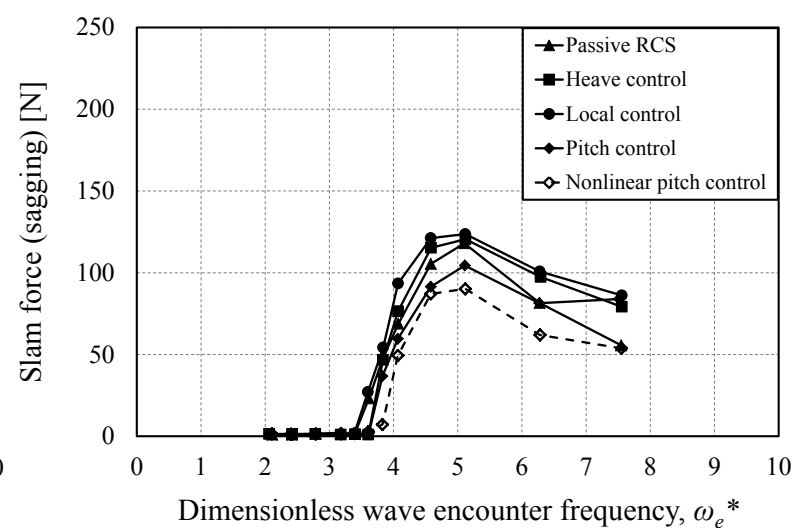

(b)

Figure 9: Sagging slam force at model speed of $2.89 \mathrm{~m} / \mathrm{s}(\mathrm{Fr}=0.608)$. (a) Wave height of $60 \mathrm{~mm}$. (b) Wave height of $90 \mathrm{~mm}$.

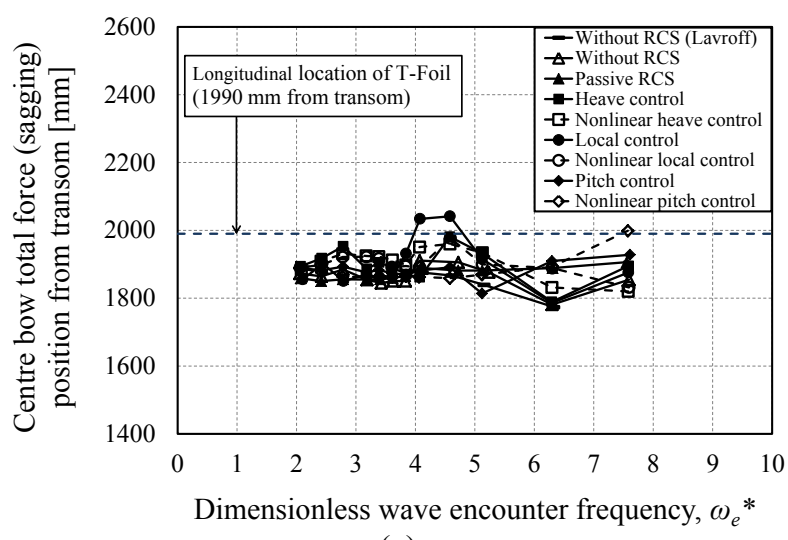

(a)

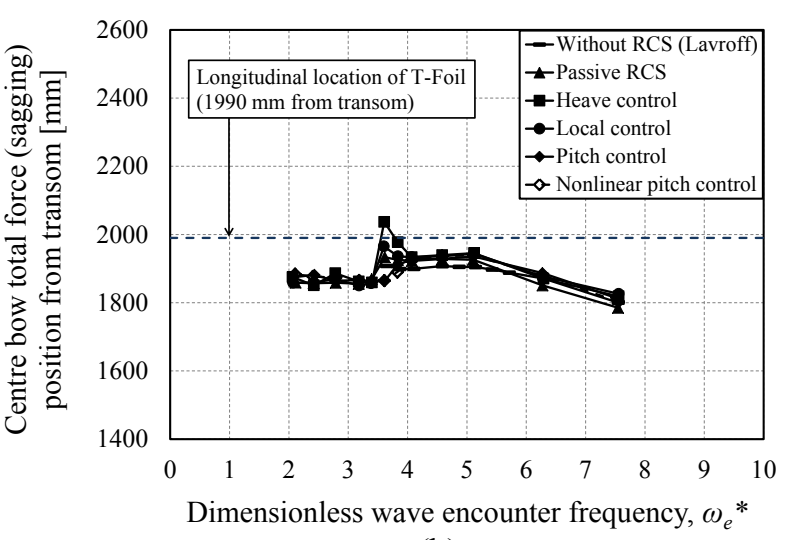

(b)

Figure 10: Centre bow total sagging force position from the transom at model speed of $2.89 \mathrm{~m} / \mathrm{s}(\mathrm{Fr}=0.608)$. (a) Wave height of $60 \mathrm{~mm}$. (b) Wave height of $90 \mathrm{~mm}$. 


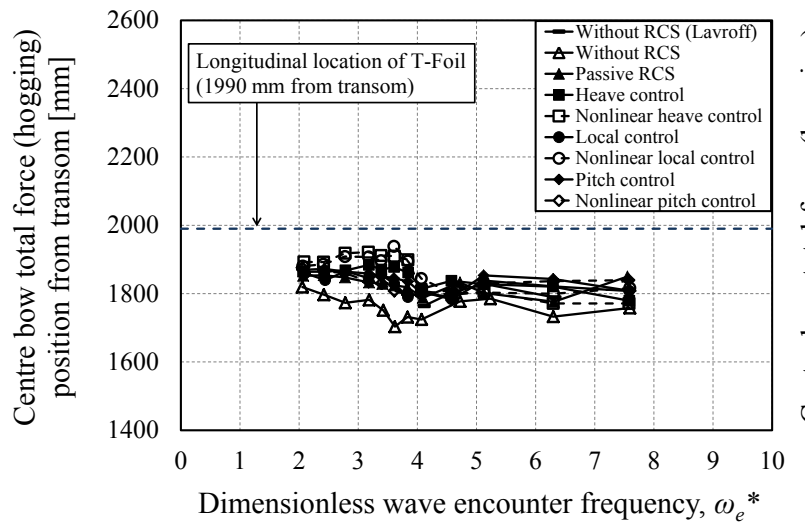

(a)

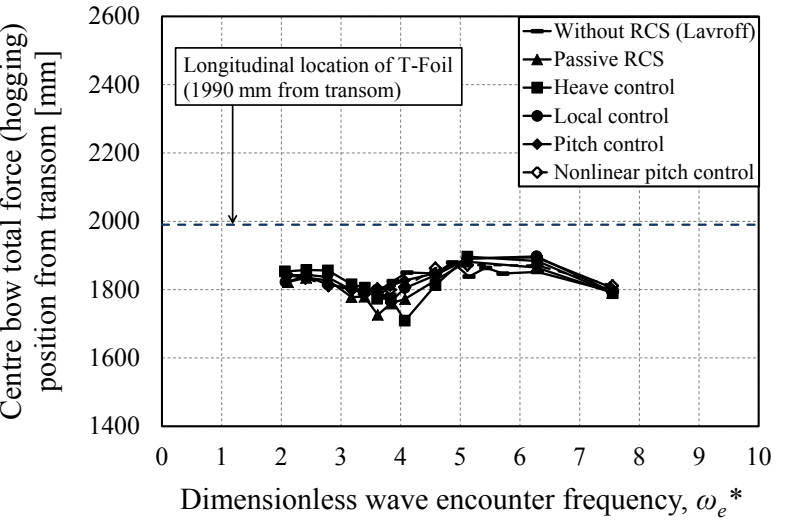

(b)

Figure 11: Centre bow total hogging force position from the transom at model speed of $2.89 \mathrm{~m} / \mathrm{s}(\mathrm{Fr}=0.608)$. (a) Wave height of $60 \mathrm{~mm}$. (b) Wave height of $90 \mathrm{~mm}$.

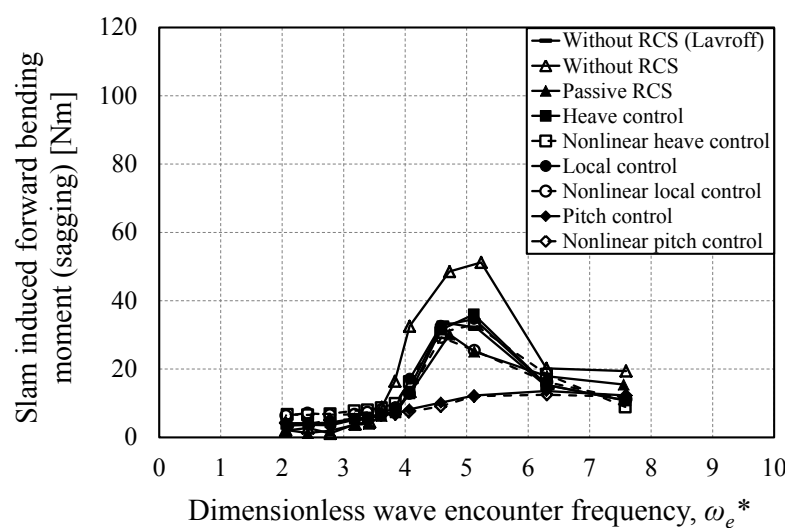

(a)

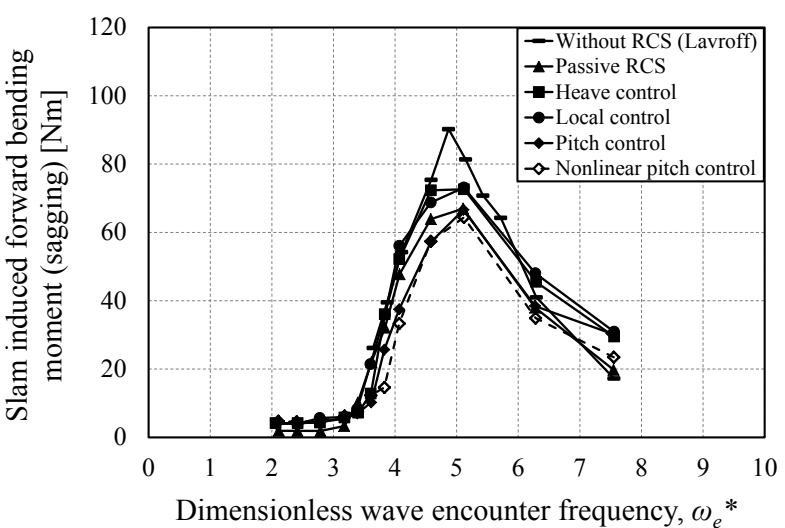

(b)

Figure 12: Demi-hull slam induced sagging bending moment at the forward segment link position at model speed of $2.89 \mathrm{~m} / \mathrm{s}(\mathrm{Fr}=0.608)$. (a) Wave height of $60 \mathrm{~mm}$. (b) Wave height of $90 \mathrm{~mm}$.

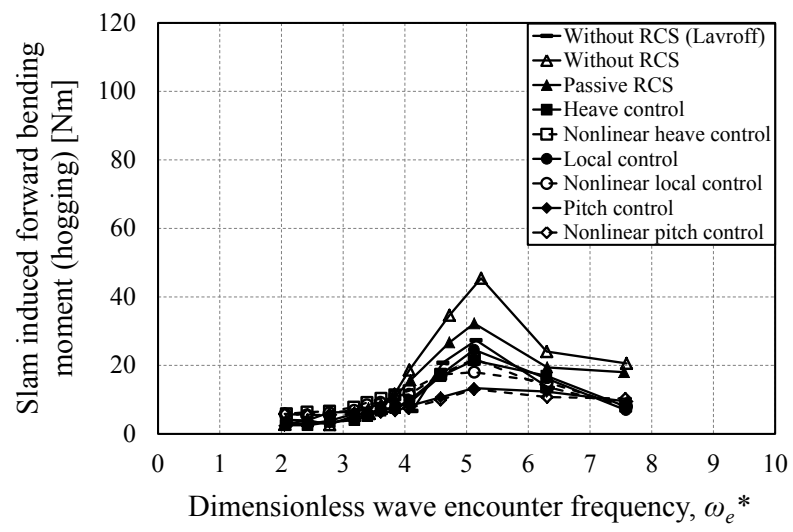

(a)

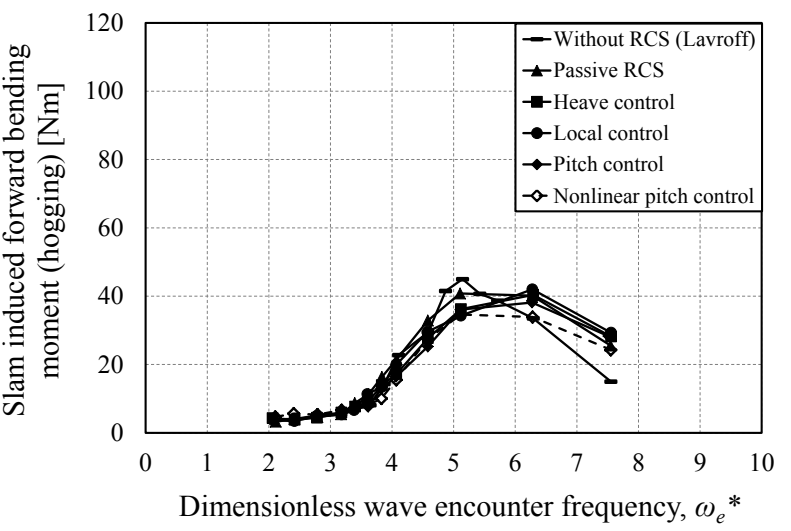

(b)

Figure 13: Demi-hull slam induced hogging bending moment at the forward segment link position at model speed of $2.89 \mathrm{~m} / \mathrm{s}(\mathrm{Fr}=0.608)$. (a) Wave height of $60 \mathrm{~mm}$. (b) Wave height of $90 \mathrm{~mm}$. 


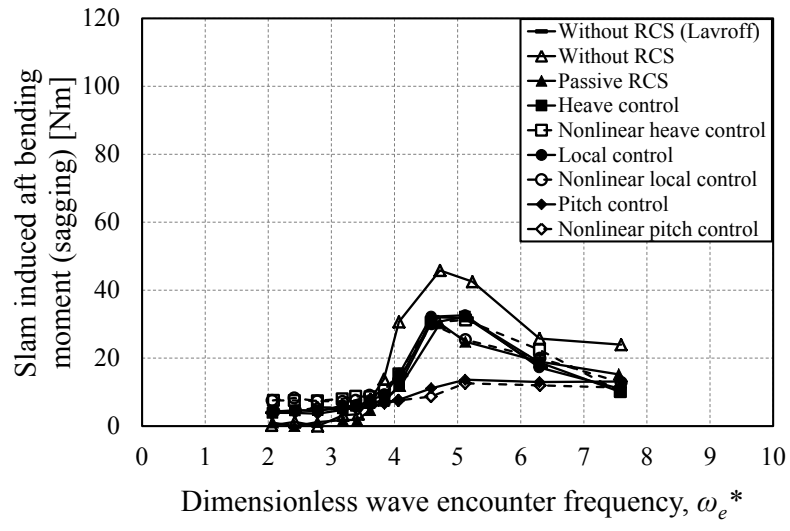

(a)

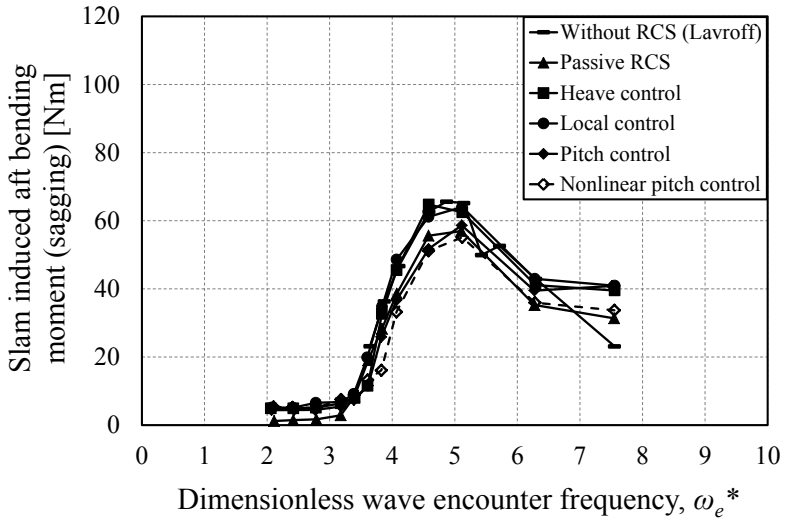

(b)

Figure 14: Demi-hull slam induced sagging bending moment at the aft segment link position at model speed of $2.89 \mathrm{~m} / \mathrm{s}(\mathrm{Fr}=0.608)$. (a) Wave height of $60 \mathrm{~mm}$. (b) Wave height of $90 \mathrm{~mm}$.

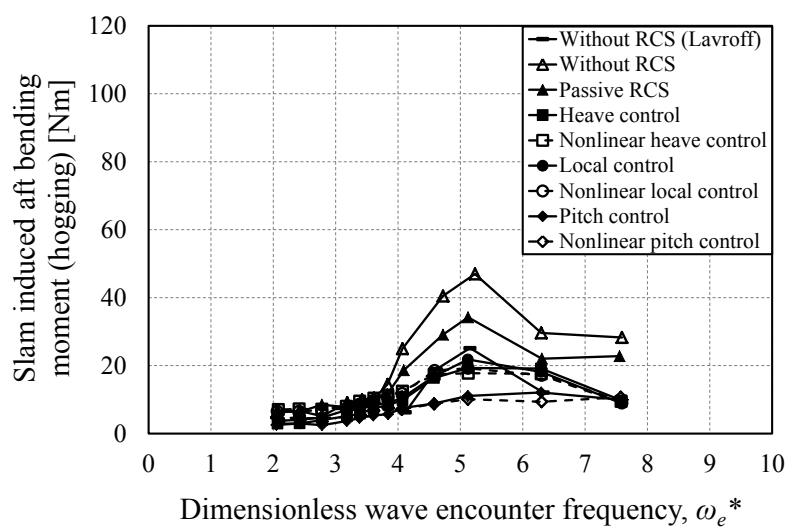

(a)

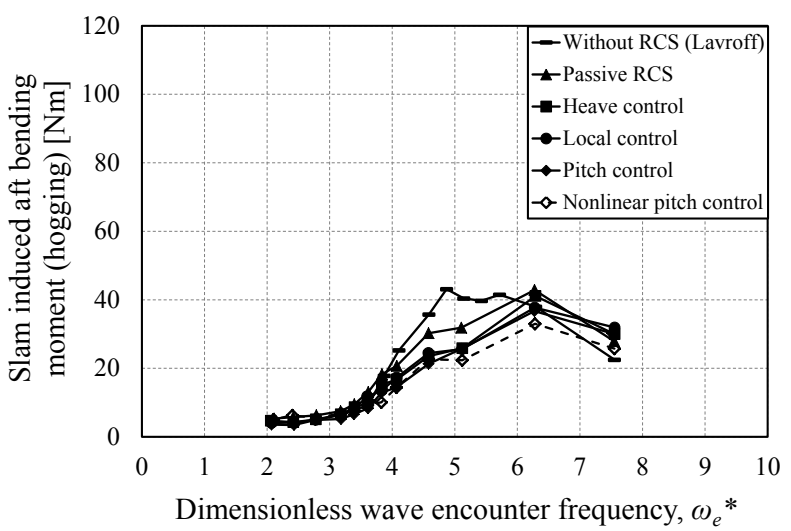

(b)

Figure 15: Demi-hull slam induced hogging bending moment at the aft segment link position at model speed of $2.89 \mathrm{~m} / \mathrm{s}(\mathrm{Fr}=0.608)$. (a) Wave height of $60 \mathrm{~mm}$. (b) Wave height of $90 \mathrm{~mm}$. 